Open Access

\title{
Time-controlled adaptive ventilation (TCAV) accelerates simulated mucus clearance via increased expiratory flow rate
}

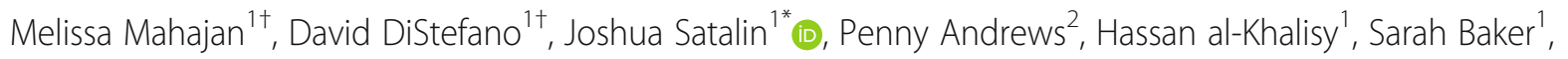
Louis A. Gatto ${ }^{3}$, Gary F. Nieman ${ }^{1}$ and Nader M. Habashi

\author{
*Correspondence: satalinj@upstate. \\ edu \\ ${ }^{\dagger}$ David DiStefano and Melissa \\ Mahajan are co-first authors who \\ contributed equally to this study. \\ ${ }^{1}$ Department of Surgery, SUNY \\ Upstate Medical University, 750 East \\ Adams St., 766 Irving Avenue, \\ Syracuse, NY 13210, USA \\ Full list of author information is \\ available at the end of the article
}

\begin{abstract}
Background: Ventilator-associated pneumonia (VAP) is the most common nosocomial infection in intensive care units. Distal airway mucus clearance has been shown to reduce VAP incidence. Studies suggest that mucus clearance is enhanced when the rate of expiratory flow is greater than inspiratory flow. The time-controlled adaptive ventilation (TCAV) protocol using the airway pressure release ventilation (APRV) mode has a significantly increased expiratory relative to inspiratory flow rate, as compared with the Acute Respiratory Distress Syndrome Network (ARDSnet) protocol using the conventional ventilation mode of volume assist control (VAC). We hypothesized the TCAV protocol would be superior to the ARDSnet protocol at clearing mucus by a mechanism of net flow in the expiratory direction.

Methods: Preserved pig lungs fitted with an endotracheal tube (ETT) were used as a model to study the effect of multiple combinations of peak inspiratory $\left(l_{P F}\right)$ and peak expiratory flow rate $\left(E_{P F}\right)$ on simulated mucus movement within the ETT. Mechanical ventilation was randomized into 6 groups ( $n=10$ runs/group): group 1-TCAV protocol settings with an end-expiratory pressure $\left(\mathrm{P}_{\text {Low }}\right)$ of $0 \mathrm{cmH}_{2} \mathrm{O}$ and $\mathrm{P}_{\text {High }} 25$ $\mathrm{cmH}_{2} \mathrm{O}$, group 2-modified TCAV protocol with increased $\mathrm{P}_{\text {Low }} 5 \mathrm{cmH}_{2} \mathrm{O}$ and $\mathrm{P}_{\text {High }}$ $25 \mathrm{cmH}_{2} \mathrm{O}$, group 3-modified TCAV with $\mathrm{P}_{\text {Low }} 10 \mathrm{cmH}_{2} \mathrm{O}$ and $\mathrm{P}_{\text {High }} 25 \mathrm{cmH}_{2} \mathrm{O}$, group 4-ARDSnet protocol using low tidal volume (LTV) and PEEP $0 \mathrm{cmH}_{2} \mathrm{O}$, group 5-ARDSnet protocol using LTV and PEEP $10 \mathrm{cmH}_{2} \mathrm{O}$, and group 6-ARDSnet protocol using LTV and PEEP $20 \mathrm{cmH}_{2} \mathrm{O}$. PEEP of ARDSnet is analogous to $P_{\text {Low }}$ of TCAV. Proximal (towards the ventilator) mucus movement distance was recorded after 1 min of ventilation in each group.

Results: The TCAV protocol groups 1, 2, and 3 generated significantly greater peak expiratory flow ( $E_{P F} 51.3 \mathrm{~L} / \mathrm{min}, 46.8 \mathrm{~L} / \mathrm{min}, 36.8 \mathrm{~L} / \mathrm{min}$, respectively) as compared to the ARDSnet protocol groups 4, 5, and $6(32.9 \mathrm{~L} / \mathrm{min}, 23.5 \mathrm{~L} / \mathrm{min}$, and $23.2 \mathrm{~L} / \mathrm{min}$, respectively) $(p<0.001)$. The TCAV groups also demonstrated the greatest proximal mucus movement $(7.95 \mathrm{~cm} / \mathrm{min}, 5.8 \mathrm{~cm} / \mathrm{min}, 1.9 \mathrm{~cm} / \mathrm{min})(p<0.01)$. All ARDSnet protocol groups (4-6) had zero proximal mucus movement $(0 \mathrm{~cm} / \mathrm{min})$.

(Continued on next page)
\end{abstract}


(Continued from previous page)

Conclusions: The TCAV protocol groups promoted the greatest proximal movement of simulated mucus as compared to the ARDSnet protocol groups in this excised lung model. The TCAV protocol settings resulted in the highest EPF and the greatest proximal movement of mucus. Increasing $P_{\text {Low }}$ reduced proximal mucus movement. We speculate that proximal mucus movement is driven by $E_{P F}$ when $E_{P F}$ is greater than $I_{P F}$, creating a net force in the proximal direction.

Keywords: Airway pressure release ventilation (APRV) mode, Expiratory flow rate, Mucus, Time-controlled adaptive ventilation (TCAV), Ventilator-associated pneumonia (VAP), ARDSnet ventilation, Volume assist control (VAC) mode, Mucus removal

\section{Background}

Despite advances in critical care medicine, VAP remains a prevalent and difficult problem in ICUs [1]. Although difficult to diagnose, the most recent practice guidelines from the American Thoracic Society and Infectious Diseases Society of America define VAP as pneumonia occurring in a patient who has been mechanically ventilated for more than 48 hours. The diagnosis is suggested by the development of a new or progressive lung infiltrate with associated signs and symptoms of infection (new onset fever, purulent sputum, leukocytosis, tachycardia, decreased oxygenation status) and is confirmed by laboratory detection of the pathogen [2].

Retention of respiratory mucus in the distal airways has been implicated as a pathogenic mechanism of VAP; it impairs immunological responses, alters normal respiratory physiology, and is highly associated with the development of pneumonia [3-6]. Mucus clearance is enhanced with ventilator settings in which the expiratory (outward) flow rate is greater than the inspiratory flow rate. The mechanism of this mucus movement is the net shear force of the airflow on the mucus in the outward direction (two-phase gas-liquid flow mechanism) [4, 7]. Benjamin et al. demonstrated that mechanical ventilation set to inverse ratio ventilation (IRV), whereby expiratory flow exceeded inspiratory flow, promoted mucus clearance in a sheep model [7]. We postulate that a mechanical ventilation strategy with a rapid expiratory as compared to inspiratory flow rate will facilitate respiratory mucus clearance similar to IRV.

Our group has developed a time-controlled adaptive ventilation (TCAV) protocol that uses the airway pressure release ventilation (APRV) mode [8, 9]. APRV is a pressure control ventilation mode characterized by a prolonged time at the inspiratory pressure and a short expiratory release. APRV set with the TCAV protocol is characterized by a significantly greater expiratory flow compared to inspiratory flow, which differs from conventional low tidal volume (LTV) ventilation. The aim of our study was to evaluate the effect of the TCAV protocol on the movement of mucus in an excised porcine lung model fitted with an endotracheal tube (ETT). We hypothesized that the increased expiratory flow rate using the TCAV protocol would cause proximal mucus movement due to a net force in the expiratory direction, improving mucus clearance from the respiratory system.

\section{Methods}

One set of preserved pig lungs (Nasco BioQuest ${ }^{\oplus}$ Inflatable Lungs Kit, product number LS03765U) fitted with a size 7.0 ETT were repeatedly subjected to multiple 
combinations of inspiratory and expiratory flow rates using two ventilation protocols, and the movement of simulated mucus was measured (Fig. 1a). The ETT was connected to the lung model and ventilator at an angle of 30 degrees above parallel. Guar gum concentrations of $0.1-1.5 \% \mathrm{w} / v$ have been shown to model the rheological properties of human respiratory mucus [10]. We chose a guar gum concentration of $1 \%$, which falls within this range $(1 \mathrm{~g}$ guar gum $/ 100 \mathrm{~mL}$ water, green food coloring). Guar gum was instilled in $3 \mathrm{~mL}$ aliquots into the middle of the ETT, and the proximal (toward the ventilator) edge of the mucus aliquot was marked (Fig. 1b). The impact of multiple mechanical ventilation strategies on mucus movement over 1 min was tested (Tables 1 and 2). Groups 1-3 utilized the TCAV protocol, which is a specific method of setting the airway pressure release ventilation (APRV) mode. A continuous positive airway pressure $(\mathrm{CPAP})$ or inspiratory time $\left(\mathrm{T}_{\mathrm{High}}\right)$ is adjusted to approximately $90 \%$ of each respiratory cycle. The CPAP phase pressure $\left(\mathrm{P}_{\mathrm{High}}\right)$ is set sufficient to recruit collapsed lung tissue and regain functional residual capacity. The expiratory time $\left(\mathrm{T}_{\mathrm{Low}}\right)$ or release phase is set using the slope of the expiratory flow curve (Slope $\mathrm{EF}_{\mathrm{EF}}$ ). Expiratory flow is stopped, and the lung is reinflated using a ratio of peak expiratory flow $\left(\mathrm{E}_{\mathrm{PF}}\right)$ to the point of expiratory flow termination $\left(\mathrm{E}_{\mathrm{FT}}\right)$ of $75 \%$ (i.e., $\mathrm{E}_{\mathrm{FT}} / \mathrm{E}_{\mathrm{PF}}=0.75$ ). Lastly, $\mathrm{P}_{\mathrm{Low}}$ is set to $0 \mathrm{cmH}_{2} \mathrm{O}$, which allows minimal impedance of expiratory flow to remove $\mathrm{CO}_{2}$ during the brief release phase and accurate assessment of lung compliance using the

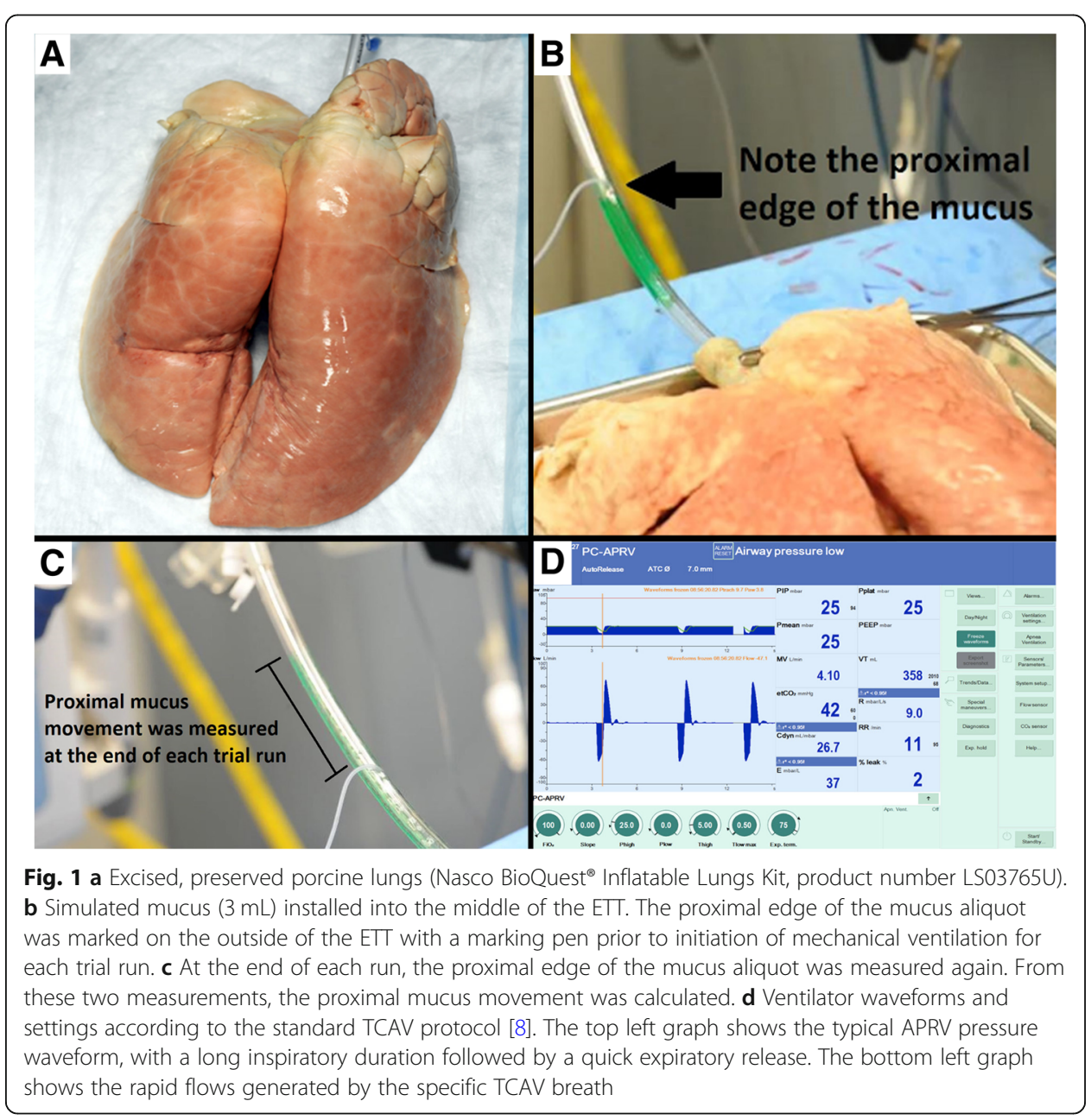


Table 1 Ventilation groups and setting for the TCAV groups 1-3

\begin{tabular}{llllll}
\hline $\begin{array}{l}\text { Group no. Mode of ventilation } \\
(n=10 \text { runs/group) }\end{array}$ & $\mathrm{E}_{\mathrm{FT}} / \mathrm{E}_{\mathrm{PF}}$ & $\mathrm{P}_{\text {High }}\left(\mathrm{cmH}_{2} \mathrm{O}\right)$ & $\mathrm{P}_{\text {Low }}\left(\mathrm{cmH}_{2} \mathrm{O}\right)$ & $\mathrm{T}_{\text {High }}(\mathrm{sec})$ & $\mathrm{T}_{\text {Low }}(\mathrm{sec})$ \\
\hline 1. TCAV protocol group 1 [8] & 0.75 & 25 & 0 & 4.5 & $0.5-0.6$ \\
2. TCAV protocol group 2 & 0.75 & 25 & 5 & 4.5 & 0.42 \\
3. TCAV protocol group 3 & 0.75 & 25 & 10 & 4.5 & $0.42-0.5$ \\
\hline
\end{tabular}

The progressive $P_{\text {Low }}$ scale was employed to generate different combinations of $I_{P F}$ and $E_{P F}$

Slope $_{\mathrm{EF}}$. However, the end-expiratory pressure never reaches 0 since the $\mathrm{T}_{\mathrm{Low}}$ is set sufficiently brief to maintain a positive end-expiratory pressure, which we term time-controlled PEEP (TC-PEEP) (Fig. 2) [8, 9]. Groups 2 and 3 utilized a modified TCAV protocol, with all of the aforementioned TCAV settings except for $\mathrm{P}_{\text {Low }}$ of 5 $\mathrm{cmH}_{2} \mathrm{O}$ (group 2) and $\mathrm{P}_{\text {Low }}$ of $10 \mathrm{cmH}_{2} \mathrm{O}$ (group 3). For groups 4-6, volume assist control (VAC) was used with the Acute Respiratory Distress Syndrome Network (ARDSnet) protocol, which uses LTV ventilation with a progressive PEEP scale.

Mucus movement was assessed by measuring the difference in centimeters between the proximal edge before and after ventilation (Fig. 1c). The primary variables that were recorded from the ventilator were peak inspiratory flow and peak expiratory flow ( $\mathrm{I}_{\mathrm{PF}}$ and $\mathrm{E}_{\mathrm{PF}}$ respectively); also recorded were peak inspiratory pressure, plateau pressure, mean airway pressure, positive end-expiratory pressure (PEEP), minute ventilation, and tidal volume. After each run, the ETT was removed and cleaned, and the porcine lungs were cleaned with saline and suctioning to clean the respiratory tree of retained simulated mucus.

Mechanical ventilation was randomized into 6 groups ( $n=10$ runs/group) with settings defined in Tables 1 and 2 . Some of the results of this study were previously published in abstract form.

\section{Statistical analysis}

For each primary variable measured (proximal mucus movement, $\mathrm{I}_{\mathrm{PF}}, \mathrm{E}_{\mathrm{PF}}$ ), data are reported as a mean with standard deviation. To compare variables between groups, a paired sample $t$ test was employed. A $p<0.05$ was considered significant. Statistical analysis was performed using JMP10.

\section{Results}

\section{Mucus clearance}

In all three TCAV groups, proximal mucus movement was measured. Proximal mucus movement was greatest with the standard TCAV protocol (group 1, $7.95 \pm 0.49 \mathrm{~cm} / \mathrm{min}$ ), followed by modified TCAV with a $\mathrm{P}_{\text {Low }} 5 \mathrm{cmH}_{2} \mathrm{O}$ (group 2, $5.83 \pm 0.50 \mathrm{~cm} / \mathrm{min}$ ) and

Table 2 Ventilation settings for the ARDSnet groups 4-6

\begin{tabular}{lllllll}
\hline $\begin{array}{l}\text { Group no. Mode of ventilation } \\
(n=10 \text { runs/group) }\end{array}$ & I:E & $\mathrm{V}_{\mathrm{T}}(\mathrm{cc})$ & $\mathrm{T}_{\mathrm{i}}(\mathrm{sec})$ & $\mathrm{RR}$ (breaths/min) & Flow $(\mathrm{L} / \mathrm{min})$ & $\mathrm{PEEP}\left(\mathrm{cmH} \mathrm{H}_{2} \mathrm{O}\right)$ \\
\hline 4. ARDSnet protocol group 4 & $1: 2$ & 240 & 1.6 & 12 & 40 & 0 \\
5. ARDSnet protocol group 5 & $1: 2$ & 240 & 1.6 & 12 & 40 & 10 \\
6. ARDSnet protocol group 6 & $1: 2$ & 240 & 1.6 & 12 & 40 & 20
\end{tabular}

Tidal volumes of $240 \mathrm{cc}$ were chosen based on ARDSnet protocol; the standard $6 \mathrm{cc} / \mathrm{kg}$ was used in a calculation for a standard $40 \mathrm{~kg}$ pig. PEEP of 0,10 , and $20 \mathrm{cmH}_{2} \mathrm{O}$ were chosen to reflect a progressive PEEP scale advocated by the ARDSnet protocol [11]. A maximum PEEP of $20 \mathrm{cmH}_{2} \mathrm{O}$ was chosen because this value generated a plateau pressure of $\sim$ $25 \mathrm{cmH}_{2} \mathrm{O}$, most similar to the plateau pressure seen in the TCAV groups 


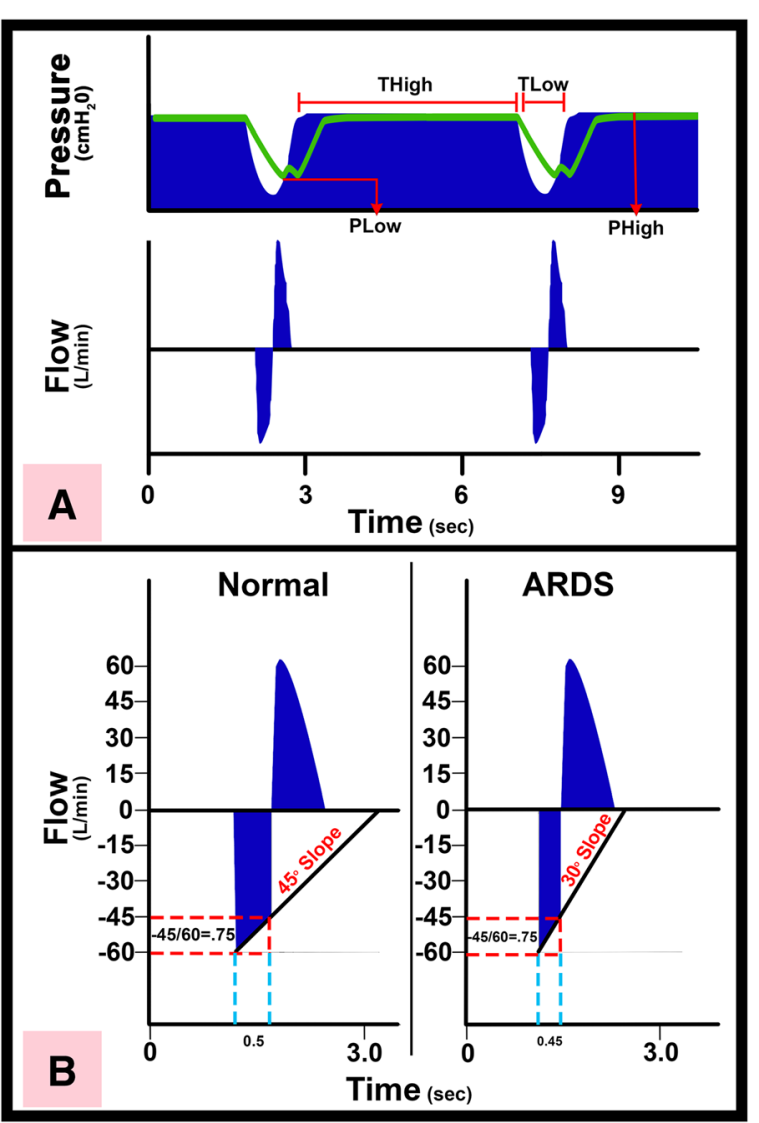

Fig. 2 Method of setting time-controlled adaptive ventilation, a protocol using APRV mode with specific settings. a Typical time-controlled adaptive ventilation (TCAV, previously referred to as personalized airway pressure release ventilation or P-APRV) airway pressure and flow curves. Correctly set TCAV has a very brief release phase ( $T_{\text {Low }}$-time at low pressure) and CPAP phase ( $T_{\text {High }}$-time at high pressure) [8]. The $T_{\text {High }}$ is $\sim 90 \%$ of each breath. The two other TCAV settings are the pressure at inspiration $\left(\mathrm{P}_{\text {High }}\right)$ and at expiration ( $\mathrm{P}_{\text {Low }}$ ), which is always programmed as $0 \mathrm{cmH}_{2} \mathrm{O}$. $\mathrm{T}_{\text {Low }}$ is sufficiently brief such that end-expiratory pressure ( $\mathrm{P}_{\text {Low }}$ ) never reaches $0 \mathrm{cmH}_{2} \mathrm{O}$ measured by the tracheal pressure (green line). $\mathbf{b}$ Alveolar stability is maintained by adaptively adjusting the expiratory duration as directed by the expiratory flow curve. The rate of lung collapse is seen in the normal (slope $45^{\circ}$ ) and acutely injured lung (ARDS, slope $30^{\circ}$ ). ARDS causes a more rapid lung collapse due to decreased lung compliance. Our studies have shown that if the end-expiratory flow ( $E_{F T} ;-45 \mathrm{~L} / \mathrm{min}$ ) to the peak expiratory flow ( $E_{P F} ;-60 \mathrm{~L} / \mathrm{min}$ ) ratio is equal to 0.75 , the resultant $T_{\text {Low }}(0.5 \mathrm{~s})$ is sufficient to stabilize alveoli $[12,13]$. The lung with ARDS collapses more rapidly such that the $\mathrm{E}_{\mathrm{FT}} / \mathrm{E}_{\mathrm{PF}}$ ratio of $75 \%$ identifies an expiratory duration of $0.45 \mathrm{~s}$ as necessary to stabilize alveoli. Figure and figure legend reproduced and modified from Jain et al. 2016 with permission [14]

modified TCAV $\mathrm{P}_{\text {Low }} 10 \mathrm{cmH}_{2} \mathrm{O}$ (group 3, $1.91 \pm 0.25 \mathrm{~cm} / \mathrm{min}$ ) ( $p<0.05$ for all groups). There was no proximal mucus movement in any of the three ARDSnet protocol groups $(0 \pm 0 \mathrm{~cm} / \mathrm{min})$ (Table 3; Fig. 3).

\section{Peak flows}

The absolute values of the $\mathrm{E}_{\mathrm{PF}}$ were significantly greater than those of the $\mathrm{I}_{\mathrm{PF}}$ for each of the TCAV groups $(p<0.05)$. In contrast, the $\mathrm{I}_{\mathrm{PF}} \mathrm{S}$ were significantly greater than the $\mathrm{E}_{\mathrm{PF}} \mathrm{S}$ for each of the LTV groups $(p<0.05)$ (Fig. 3). APRV set with the standard TCAV protocol (group 1, $\mathrm{P}_{\text {Low }}$ ) generated the highest $\mathrm{E}_{\mathrm{PF}}$ of all TCAV groups $(51.27 \pm 0.45 \mathrm{~L} / \mathrm{min})$. As the $\mathrm{P}_{\mathrm{Low}}$ was increased in the modified TCAV modes (groups 2 and 3), the $\mathrm{E}_{\mathrm{PF}}$ and $\mathrm{I}_{\mathrm{PF}}$ 
Table 3 Primary and secondary outcomes recorded

\begin{tabular}{|c|c|c|c|c|c|c|}
\hline & $\begin{array}{l}\text { TCAV, P Pow } 0 \\
\text { (standard) }\end{array}$ & $\begin{array}{l}\text { TCAV, } \\
\text { PLow } 5\end{array}$ & $\begin{array}{l}\text { TCAV, } \\
\text { PLow } 10^{\text {Le }}\end{array}$ & $\begin{array}{l}\text { LTV, } \\
\text { PEEP } 0\end{array}$ & $\begin{array}{l}\text { LTV, } \\
\text { PEEP } 10\end{array}$ & $\begin{array}{l}\text { LTV, } \\
\text { PEEP } 20\end{array}$ \\
\hline $\begin{array}{l}\text { Mucus movement } \\
(\mathrm{cm} / \mathrm{min})\end{array}$ & $7.95 \pm 0.49$ & $5.83 \pm 0.50$ & $1.91 \pm 0.25$ & $0 \pm 0$ & $0 \pm 0$ & $0 \pm 0$ \\
\hline$I_{P F}(L / m i n)$ & $44.04 \pm 0.63$ & $35.37 \pm 0.48$ & $28.88 \pm 0.62$ & $45.06 \pm 0.42$ & $44.68 \pm 0.23$ & $44.11 \pm 0.96$ \\
\hline $\mathrm{E}_{\mathrm{PF}}(\mathrm{L} / \mathrm{min})$ & $51.27 \pm 0.45$ & $46.84 \pm 0.35$ & $36.76 \pm 0.44$ & $32.94 \pm 0.58$ & $23.52 \pm 0.21$ & $23.16 \pm 0.61$ \\
\hline $\mathrm{PIP}\left(\mathrm{cmH}_{2} \mathrm{O}\right)$ & $25 \pm 0$ & $25 \pm 0$ & $25 \pm 0$ & $23.4 \pm 0.72$ & $26 \pm 0.54$ & $37.9 \pm 0.23$ \\
\hline$P_{\text {Plat }}\left(\mathrm{cmH}_{2} \mathrm{O}\right)$ & $24.9 \pm 0.1$ & $24.9 \pm 0.1$ & $25 \pm 0$ & $10.08 \pm 0.10$ & $15 \pm 0$ & $26.81 \pm 0.7$ \\
\hline $\mathrm{P}_{\text {Mean }}\left(\mathrm{cmH}_{2} \mathrm{O}\right)$ & $21.8 \pm 0.13$ & $22.8 \pm 0.13$ & $23 \pm 0$ & $4.45 \pm 0.05$ & $12.7 \pm 0.15$ & $23.4 \pm 0.16$ \\
\hline PEEP $\left(\mathrm{cmH}_{2} \mathrm{O}\right)$ & N/A & N/A & N/A & $0.57 \pm 0.02$ & $10 \pm 0$ & $20.2 \pm 0.2$ \\
\hline $\mathrm{MV}(\mathrm{L} / \mathrm{min})$ & $6.28 \pm 0.15$ & $4.01 \pm 0.8$ & $3.63 \pm 0.12$ & $3.01 \pm 0.02$ & $3.08 \pm 0.03$ & $3.13 \pm 0.08$ \\
\hline $\mathrm{V}_{\mathrm{T}}(\mathrm{cc})$ & $491.6 \pm 11.61$ & $315.5 \pm 3.15$ & $271.56 \pm 5.91$ & $243.4 \pm 1.65$ & $245.3 \pm 1.45$ & $241.2 \pm 0.36$ \\
\hline
\end{tabular}

All values are reported in mean $\pm S E$. TCAV time-controlled adaptive ventilation, $L T V$ low tidal volume, $I_{P F}$ peak inspiratory flow, $E_{P F}$ peak expiratory flow, PIP peak inspiratory pressure, $P_{\text {Plat }}$ plateau pressure, $P_{\text {Mean }}$ mean airway pressure, $P E E P$ positive end-expiratory pressure, $M V$ minute ventilation, $V_{T}$ tidal volume. Proximal mucus movement was significantly different between all groups $(p<0.05)$, except ARDSnet groups 4,5 , and 6 . $\mathrm{E}_{\mathrm{PF}}$ was significantly different between all groups $\left(p<0.05\right.$ ), except ARDSnet groups 5 and 6 . Regarding $I_{P F}$, there was no significant difference between TCAV group 1 and ARDSnet groups 4, 5, and 6; however, groups 1, 4, 5, and 6 had significantly greater $I_{\mathrm{PF}}$ than TCAV groups 2 and $3(p<0.05)$

decreased. For the ARDSnet groups, the $\mathrm{E}_{\mathrm{PF}}$ decreased as PEEP was increased from PEEP 0 (group 4, 32.94 $\pm 0.58 \mathrm{~L} / \mathrm{min}$ ) to PEEP 10 (group 5, $23.52 \pm 0.21 \mathrm{~L} / \mathrm{min}$ ), but plateaued after that with PEEP 20 (group 6, $23.16 \pm 0.61 \mathrm{~L} / \mathrm{min}$ ). There was no significant difference in $\mathrm{I}_{\mathrm{PF}}$ between all ARDSnet groups and the TCAV group $1(p=0.61)$ (Table 3, Fig. 3); however, the $\mathrm{I}_{\mathrm{PF}}$ in the ARDSnet groups were significantly greater than that of the TCAV groups 2 and 3 ( $p<0.05$ for both).

\section{Mucus movement and $\mathrm{E}_{\mathrm{PF}}$}

Proximal mucus movement was most closely associated with the absolute value of $\mathrm{E}_{\mathrm{PF}}$ in the TCAV groups, where $\mathrm{E}_{\mathrm{PF}}>\mathrm{I}_{\mathrm{PF}}$. We found a strong positive correlation between $\mathrm{E}_{\mathrm{PF}}$ and mucus movement among these groups $\left(R^{2}=0.74\right)$ (Fig. 4). There was no association between proximal mucus movement and $E_{P F}$ in the ARDSnet groups, where $\mathrm{I}_{\mathrm{PF}}>\mathrm{E}_{\mathrm{PF}}$.

\section{Discussion}

The findings presented in this manuscript demonstrate that the TCAV protocol, using the APRV mode, resulted in proximal mucus clearance in our isolated lung model. If the TCAV protocol is also effective at facilitating mucus removal in patients, it could have important clinical ramifications. Treatment groups 4 through 6 were based on the ARDSnet protocol, which was chosen because it is the standard-of-care method for protective mechanical ventilation. Walkey et al. studied the incidence of VAP in ICU patients with pulmonary contusion and found that use of APRV was associated with less VAP, which they hypothesized was due to increased lung recruitment [15]. Although the TCAV protocol was not used in the Walkey et al. study, we showed that even if APRV was not set to the standard TCAV protocol (groups 2 and 3), there was still proximal mucus movement. Hence, we postulate that an additional or alternate mechanism for this clinical finding could be increased respiratory mucus clearance due 


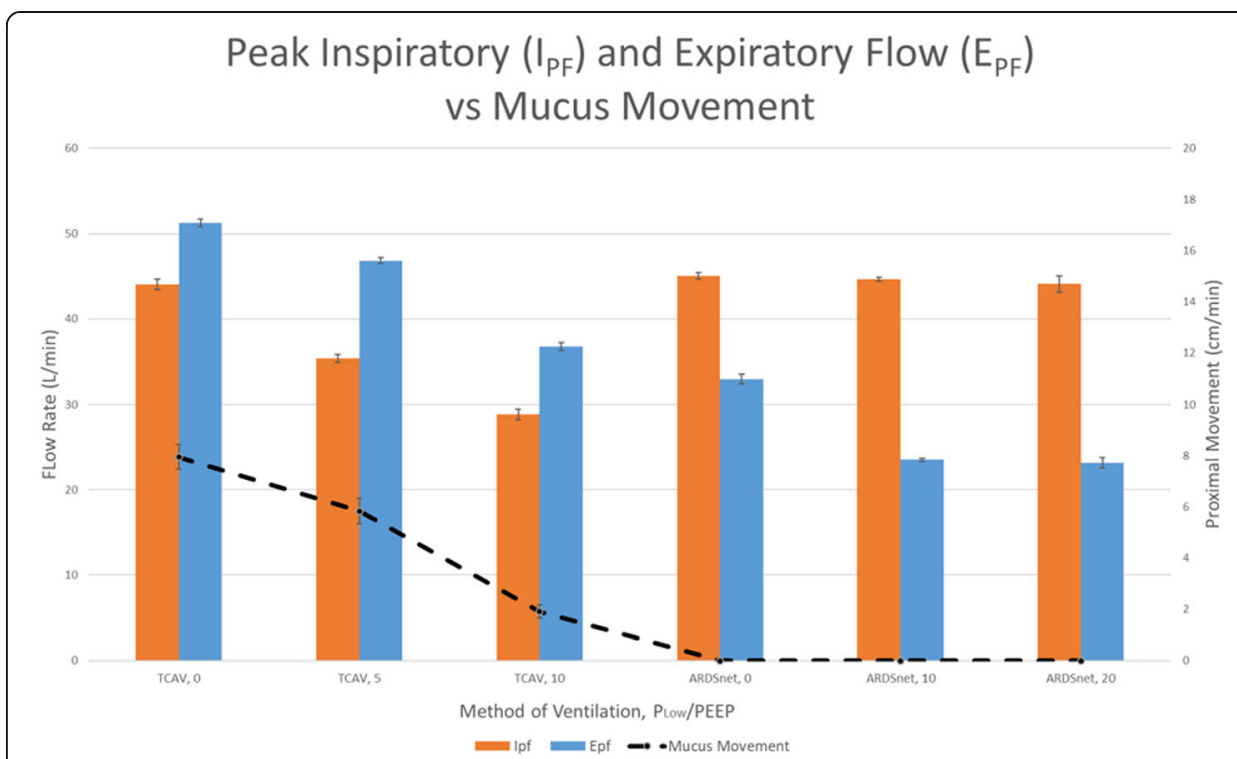

Fig. 3 Combined bar/line graph comparing the peak inspiratory flow (l $\left.\mathrm{PF}_{\mathrm{PF}}\right)$, peak expiratory flow ( $\left.\mathrm{E}_{\mathrm{PF}}\right)$, and proximal mucus movement for the different experimental groups. The $I_{P F}$ and $E_{P F}$ are indicated by the orange and blue colored bars, respectively, and correspond to the left vertical axis. Proximal mucus movement is indicated by the data points connected by the dotted line and corresponds to the right vertical axis. TCAV protocol groups 1, 2, and 3 utilized APRV with varying $P_{\text {Low }}$ settings of $0 \mathrm{cmH}_{2} \mathrm{O}$ (standard TCAV), $5 \mathrm{cmH}_{2} \mathrm{O}$, and $10 \mathrm{cmH}_{2} \mathrm{O}$, respectively. ARDSnet protocol groups 4, 5, and 6 utilized LTV with varying PEEP settings of $0 \mathrm{cmH}_{2} \mathrm{O}, 10 \mathrm{cmH}_{2} \mathrm{O}$, and $20 \mathrm{cmH}_{2} \mathrm{O}$, respectively

to the high expiratory flows seen with the APRV mode. In fact, these effects might be additive. In the collapsed state, the lung cannot be cleared of mucus and is prone to pneumonia [16]. In the recruited lung, the open airways permit mucus movement and decrease the risk of pneumonia. Hence, the increased lung recruitment and postulated mucus clearance characteristic of APRV may work together to decrease the incidence of VAP.

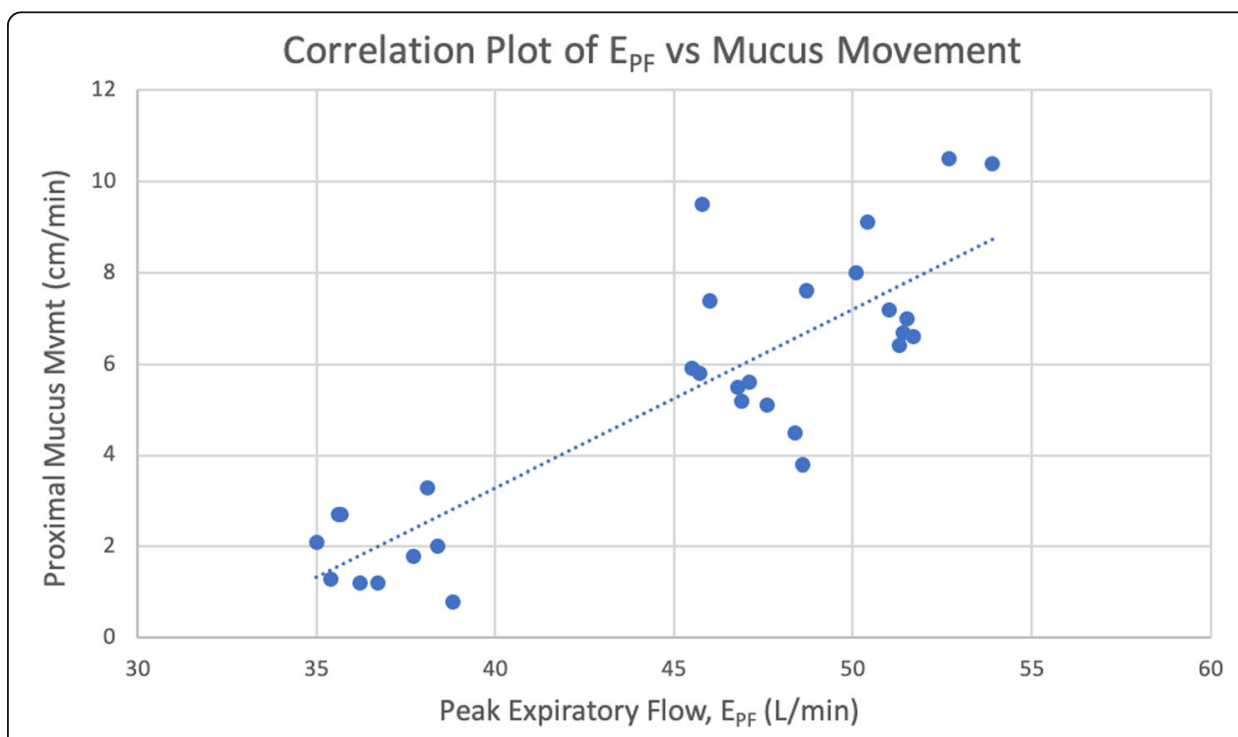

Fig. 4 Scatterplot of $E_{P F}$ and proximal mucus movement for all trials within the TCAV groups $(n=30)$ with a line of best fit, for which $R^{2}=0.74$ 
Our data suggests that the combination of time and pressure parameters of the TCAV protocol effectively generates high expiratory flows. This protocol recruits the lung with each breath cycle, creating greater elastic recoil forces and increasing potential energy. This is then liberated as kinetic energy during the pressure release phase. During the brief release phase, lung recoil generates the relatively high expiratory flow rates measured in this study. In contrast, the ARDSnet protocol delivers a low tidal volume to the lung over a short inspiratory duration, which does not generate the same degree of pressure or elastic energy within the lung and leads to a significantly lower expiratory flow rate. It is due to this concept that the TCAV groups with increased $\mathrm{P}_{\text {Low }}$ (groups 2 and 3 ) still showed a significantly greater expiratory to inspiratory flow ratio; although there was some impedance to expiratory flow, the expiratory flow rate was still greater than inspiratory flow rate.

ARDSnet group 6 generated a plateau pressure $\left(\mathrm{P}_{\text {Plat }}, 26.81 \pm 0.07 \mathrm{cmH}_{2} \mathrm{O}\right)$ most similar to the TCAV groups $\left(25 \pm 0.0 \mathrm{cmH}_{2} \mathrm{O}\right)$; however, the time spent at this pressure is different between the two protocols. The TCAV protocol's increased time at plateau pressure produces a more complete recruitment with an increase in alveolar number rather than size [12]. As lung volume increases, airways are tethered open which lowers airway resistance to gas flow [13]. In other words, the higher mean airway pressures "stent" open the lungs, which lowers expiratory resistance and allows for greater peak expiratory flows. While ARDSnet group 6 generated a similar plateau pressure to the TCAV groups, the relatively short time at inspiration did not allow pressure or energy to build in the lung in the same manner, which is evidenced by the net flow in the inspiratory direction seen with ARDSnet.

Notably, the higher plateau pressures that facilitate lung recruitment in TCAV have not been associated with an increased risk of ventilator-induced lung injury (VILI). Indeed, previous studies using TCAV have shown that the extended time at $\mathrm{P}_{\text {Plat }}$ has the beneficial effect of redistributing gas to the alveoli from the alveolar ducts and promoting homogenous alveolar ventilation, rather than overdistending alveoli and causing VILI $[8,9]$. The extended time at $\mathrm{T}_{\text {High }} / \mathrm{P}_{\text {High }}$ gradually recruits alveolar units in a non-pathologic manner, leading to increased lung volume and reduced strain at the alveolar level, despite the higher $\mathrm{P}_{\text {Plat }}[12,13,17]$. A systematic review has shown that preemptive application of TCAV on trauma patients demonstrated a reduced ARDS incidence and mortality [18].

The TCAV groups, especially the standard protocol group 1, demonstrated significant proximal mucus movement whereas the ARDSnet groups showed no effect on mucus movement. We believe this is due to the difference in flows generated by each ventilation mode. For the TCAV groups, the $\mathrm{E}_{\mathrm{PF}} \mathrm{S}$ were significantly greater than the $\mathrm{I}_{\mathrm{PF}} \mathrm{S}$ which resulted in a net flow in the expiratory direction; the opposite was true for the ARDSnet groups. Hence, we postulated that this net expiratory force at least partially explains the mechanism for proximal mucus clearance. We also observed a trend between increasing $\mathrm{E}_{\mathrm{PF}}$ values and increasing proximal mucus movement for the groups with $\mathrm{E}_{\mathrm{PF}}>\mathrm{I}_{\mathrm{PF}}$. Group 1 (standard TCAV protocol) had the greatest $\mathrm{E}_{\mathrm{PF}}$ and the greatest proximal mucus movement, followed by group 2 and then group 3 . This positive correlation is shown in Fig. $4\left(R^{2}=0.74\right)$. We found a greater $\mathrm{I}_{\mathrm{PF}}$ than $\mathrm{E}_{\mathrm{PF}}$ for all ARDSnet groups, which caused a net inspiratory force in the distal (toward the lungs) direction. We believe this force prevented proximal mucus movement. Although the study model 
did not allow distal mucus movement to be observed or measured, we postulate that the simulated mucus was driven into the lung due to the net flow in the inspiratory direction, among other variables.

One might expect the mucus movement to be influenced by the magnitude of the vector force in the expiratory direction, which is represented by the difference between $\mathrm{E}_{\mathrm{PF}}$ and $\mathrm{I}_{\mathrm{PF}}$. However, we found that, when the $\mathrm{E}_{\mathrm{PF}}$ was greater than the $\mathrm{I}_{\mathrm{PF}}$ mucus movement correlated much more with the absolute value of the $\mathrm{E}_{\mathrm{PF}}\left(R^{2}=0.74\right.$, Fig. 4) rather than with the magnitude of the vector force in the expiratory direction $\left(R^{2}=0.002\right)$. This finding is supported by Kim et al., who also found that respiratory mucus movement was influenced most greatly by the absolute $\mathrm{E}_{\mathrm{PF}}$ value rather than the difference between $\mathrm{E}_{\mathrm{PF}}$ and $I_{P F}$ [4]. Although the ARDSnet group 1 (PEEP 0) generated an $E_{P F}$ value similar to TCAV group 3 ( $\mathrm{P}_{\text {Low }} 10$ ) (32.94 vs. $36.76 \mathrm{~L} / \mathrm{min}$, respectively), the ARDSnet group still did not generate any proximal mucus movement. We believe this is because the $\mathrm{I}_{\mathrm{PF}}$ was greater than the $\mathrm{E}_{\mathrm{PF}}$ in ARDSnet group, instead of vice versa, which creates a net force in the inspiratory direction.

There are limitations to our study. Due to IACUC regulations of minimal animal use, an ex vivo porcine lung model was used to obtain the data for this study. Accordingly, we cannot be sure how our results will translate to an in vivo or clinical setting due to variables missing from our study, such as chest wall resistance. Due to the chest wall tendency to expand, it would be expected that this would provide a slight opposing force during the expiratory phase of the TCAV breath protocol. We postulate this might affect the magnitude of the $\mathrm{E}_{\mathrm{PF}}$ and mucus movement that was observed. Though we found that $\mathrm{E}_{\mathrm{PF}}$ (when $\mathrm{E}_{\mathrm{PF}}>\mathrm{I}_{\mathrm{PF}}$ ) and mucus movement had the strongest correlation across variables, we cannot definitively conclude that $\mathrm{E}_{\mathrm{PF}}$ is the primary mechanism for proximal mucus movement. Numerous other factors (mean airway pressure, minute ventilation, etc.) vary among the experiment groups, and their effect on mucus movement cannot clearly be quantified. However, we do conclude with reasonable certainty that $E_{P F}$ (when $E_{P F}>I_{P F}$ ) accounts for at least a significant part of the results for proximal mucus movement seen here. Another limitation is that we washed and reused the same set of porcine lungs for all experiments. Any retained mucus beyond reach of the standard cleanout, or perhaps the cleanout process itself, could have altered the distal airways and impacted the later trials. Our model also limited us to measuring mucus distance within the ETT; it did not allow us to see how mucus moved within the bronchi and beyond. Applied clinically, much of the mucus driven by the TCAV protocol from the distal airways to the ETT might get stuck around the cuff of the ETT. This could theoretically be remedied with suctioning just beyond the tip of the ETT. Additionally, the ventilation mode alone would not be able to clear secretions that get stuck on the proximal side of the ETT cuff. These subglottic secretions are outside of the ETT and therefore not exposed to the ventilatory flows. However, subglottic secretion drainage methods already used clinically could supplement our TCAV strategy to maximize secretion clearance.

In summary, we demonstrated that a ventilation strategy (TCAV protocol) could be used to move mucus proximally in an isolated lung model. We postulate that the mechanism of proximal mucus movement is a combination of absolute expiratory flow rate and the net force vector in the expiratory direction. The current standard-of-care protective ventilation strategy (ARDSnet protocol) did not result in proximal mucus movement. 


\title{
Conclusions
}

The TCAV protocol resulted in the greatest proximal movement of simulated mucus in this excised porcine pulmonary system model. Proximal mucus movement was most strongly correlated with the absolute $\mathrm{E}_{\mathrm{PF}}$ when the net flow rate was in the expiratory direction $\left(\mathrm{E}_{\mathrm{PF}}>\mathrm{I}_{\mathrm{PF}}\right)$. The ARDSnet protocol did not move simulated mucus proximally, even when generating expiratory flows similar to those seen in one of the TCAV protocol groups. We postulate that the increased $\mathrm{E}_{\mathrm{PF}}$ relative to $\mathrm{I}_{\mathrm{PF}}$ generated in the TCAV protocol is the probable mechanism for the proximal mucus movement measured in this study. We further speculate that if the TCAV protocol is applied clinically and has the same impact on increased mucus clearance in patients, it may reduce the incidence, morbidity, and mortality associated with VAP.

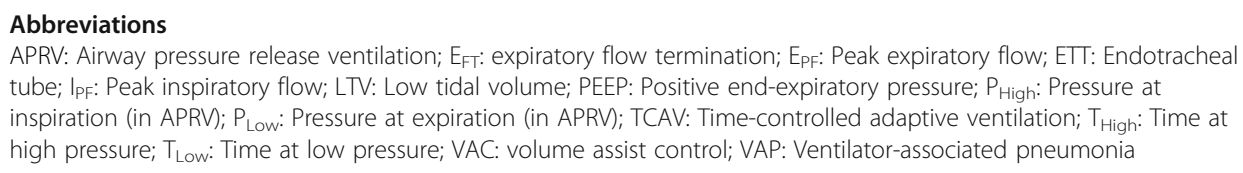
tube; IPF: Peak inspiratory flow; LTV: Low tidal volume; PEEP: Positive end-expiratory pressure; PHigh: Pressure at inspiration (in APRV); $P_{\text {Low: }}$ Pressure at expiration (in APRV); TCAV: Time-controlled adaptive ventilation; $T_{\text {High: Time at }}$ high pressure; $T_{\text {Low: }}$ Time at low pressure; VAC: volume assist control; VAP: Ventilator-associated pneumonia

\author{
Acknowledgements \\ N/A \\ Funding \\ Salary support for JS, SB, GFN from NIH R01 HL131143.
}

\section{Availability of data and materials}

Data obtained for this manuscript will be held on a secured server and backed up at SUNY Upstate Medical Center and will be available to the public on request.

\section{Authors' contributions}

DD, MM, JS, PA, GFN, and NMH conceived and designed the study. DD, MM, and JS acquired the data. DD, MM, JS, and GFN drafted the manuscript. DD, MM, JS, HAK, SB, PA, LAG, NMH, and GFN contributed to the critical revisions. All authors read and approved the final manuscript.

Ethics approval and consent to participate

N/A

\section{Consent for publication}

N/A

\section{Competing interests}

PA, GFN, and NMH have presented and received honoraria and/or travel reimbursement at event(s) sponsored by Dräger Medical Systems, Inc., outside of the published work. PLA, GFN, NMH, and LAG have lectured for Intensive Care Online Network, Inc. (ICON). NMH is the founder of ICON, of which PLA is an employee. NMH holds patents on a method of initiating, managing, and/or weaning airway pressure release ventilation, as well as controlling a ventilator in accordance with the same, but these patents are not commercialized, licensed, nor royalty-producing. The authors maintain that industry had no role in the design and conduct of the study; the collection, management, analysis, or interpretation of the data; nor the preparation, review, or approval of the manuscript. The other authors declare that they have no competing interests.

\section{Publisher's Note}

Springer Nature remains neutral with regard to jurisdictional claims in published maps and institutional affiliations.

\section{Author details}

${ }^{1}$ Department of Surgery, SUNY Upstate Medical University, 750 East Adams St., 766 Irving Avenue, Syracuse, NY 13210, USA. ${ }^{2}$ Department of Trauma Critical Care Medicine, R Adams Cowley Shock Trauma Center, University of Maryland School of Medicine, 22 S. Greene Street, Baltimore, MD 21201, USA. ${ }^{3}$ Department of Biological Sciences, SUNY Cortland, 22 Graham Avenue, Cortland, NY 13045, USA.

Received: 22 January 2019 Accepted: 29 April 2019

Published online: 16 May 2019

References

1. Hunter JD (2012) Ventilator associated pneumonia. Bmj 344:e3325 
2. American Thoracic S, Infectious Diseases Society of A (2005) Guidelines for the management of adults with hospitalacquired, ventilator-associated, and healthcare-associated pneumonia. Am J Respir Crit Care Med 171:388-416

3. de Prost N, Roux D, Dreyfuss D, Ricard JD, Le Guludec D, Saumon G (2007) Alveolar edema dispersion and alveolar protein permeability during high volume ventilation: effect of positive end-expiratory pressure. Intensive Care Med 33:711-717

4. Kim CS, Iglesias AJ, Sackner MA (1987) Mucus clearance by two-phase gas-liquid flow mechanism: asymmetric periodic flow model. J Appl Physiol 62:959-971

5. Dennesen P, Veerman E, van Nieuw Amerongen A, Jacobs J, Kessels A, van der Keybus P, Ramsay G, van der Ven A (2003) High levels of sulfated mucins in bronchoalveolar lavage fluid of ICU patients with ventilator-associated pneumonia. Intensive Care Med 29:715-719

6. Powell J, Garnett JP, Mather MW, Cooles FAH, Nelson A, Verdon B, Scott J, Jiwa K, Ruchaud-Sparagano MH, Cummings SP, Perry JD, Wright SE, Wilson JA, Pearson J, Ward C, Simpson AJ (2018) Excess mucin impairs subglottic epithelial host defense in mechanically ventilated patients. Am J Respir Crit Care Med 198:340-349

7. Benjamin RG, Chapman GA, Kim CS, Sackner MA (1989) Removal of bronchial secretions by two-phase gas-liquid transport. Chest 95:658-663

8. Habashi NM (2005) Other approaches to open-lung ventilation: airway pressure release ventilation. Crit Care Med 33 S228-S240

9. Nieman GF, Andrews P, Satalin J, Wilcox K, Kollisch-Singule M, Madden M, Aiash H, Blair SJ, Gatto LA, Habashi NM (2018) Acute lung injury: how to stabilize a broken lung. Critical Care 22:136

10. King M, Zahm JM, Pierrot D, Vaquez-Girod S, Puchelle E (1989) The role of mucus gel viscosity, spinnability, and adhesive properties in clearance by simulated cough. Biorheology 26:737-745

11. ARDSnet (2000) Ventilation with lower tidal volumes as compared with traditional tidal volumes for acute lung injury and the acute respiratory distress syndrome. The Acute Respiratory Distress Syndrome Network. New Engl J Med 342: $1301-1308$

12. Kollisch-Singule $M$, Jain S, Andrews P, Smith BJ, Hamlington-Smith KL, Roy S, DiStefano D, Nuss E, Satalin J, Meng QH, Marx W, Bates JHT, Gatto LA, Nieman GF, Habashi NM (2016) Effect of airway pressure release ventilation on dynamic alveolar heterogeneity. JAMA Surg 151:64-72

13. Kollisch-Singule M, Emr B, Smith B, Ruiz C, Roy S, Meng Q, Jain S, Satalin J, Snyder K, Ghosh A, Marx WH, Andrews P, Habashi N, Nieman GF, Gatto LA (2014) Airway pressure release ventilation reduces conducting airway micro-strain in lung injury. J Am Coll Surg 219:968-976

14. Jain SV, Kollisch-Singule M, Sadowitz B, Dombert L, Satalin J, Andrews P, Gatto LA, Nieman GF, Habashi NM (2016) The 30-year evolution of airway pressure release ventilation (APRV). Intensive Care Med Exp 4:11

15. Walkey AJ, Nair S, Papadopoulos S, Agarwal S, Reardon CC (2011) Use of airway pressure release ventilation is associated with a reduced incidence of ventilator-associated pneumonia in patients with pulmonary contusion. J Trauma 70:E42-E47

16. Brooks-Brunn JA (1995) Postoperative atelectasis and pneumonia. Heart Lung 24:94-115

17. Kollisch-Singule M, Emr B, Smith B, Roy S, Jain S, Satalin J, Snyder K, Andrews P, Habashi N, Bates JH, Marx W, Nieman G, Gatto L (2014) Mechanical breath profile of APRV maximizes alveolar recruitment and minimizes micro-strain in acute lung injury. JAMA Surg In Press

18. Andrews PL, Shiber JR, Jaruga-Killeen E, Roy S, Sadowitz B, O'Toole RV, Gatto LA, Nieman GF, Scalea T, Habashi NM (2013) Early application of airway pressure release ventilation may reduce mortality in high-risk trauma patients: a systematic review of observational trauma ARDS literature. J Trauma Acute Care Surg 75:635-641

\section{Submit your manuscript to a SpringerOpen ${ }^{\circ}$ journal and benefit from:}

- Convenient online submission

- Rigorous peer review

- Open access: articles freely available online

- High visibility within the field

- Retaining the copyright to your article

Submit your next manuscript at $>$ springeropen.com 